Article

\title{
Mobility-Related Economic Exclusion: Accessibility and Commuting Patterns in Industrial Zones in Turkey
}

\author{
Nihan Akyelken \\ Sustainable Urban Development Programme, Department for Continuing Education, University of Oxford, OX1 2JA, Oxford, \\ UK; E-Mail: nihan.akyelken@conted.ox.ac.uk
}

Submitted: 20 August 2017 | Accepted: 2 November 2017 | Published: 28 December 2017

\begin{abstract}
Geographers have long examined the assumption that women are locally constricted and what this means for women taking up of economic opportunities. These studies have provided valuable insights into the understanding of the spatial dimension of social exclusion. However, the investigation of the role of wider economic, physical and social contexts on women's mobility and accessibility constraints has mainly concerned the countries in North America and Western Europe. Through a mixed methods study of two industrial zones in Turkey, this article looks at how women and men from different social backgrounds access the zones with the aim of identifying the specific constraints that women face in their everyday life in accessing economic opportunities. The results show that while gender seems to play a role in the choice of place of residence and the employers' perception of time use, women's socioeconomic and educational backgrounds seem to be more important predictors of their commuting patterns and access to the zones. The study confirms that gendered daily travel patterns are a useful unit of analysis for investigating unequal access to economic opportunities. It further argues that the complex nature of everyday mobilities of women should be interpreted in conjunction with the perceptions of employers on women's work spaces and time use.
\end{abstract}

\section{Keywords}

accessibility; commuting; female labour; industrial zones; labour markets; mobility; Turkey

\section{Issue}

This article is part of the issue "Regional and Urban Mobility: Contribution to Social Inclusion", edited by Janet Stanley (University of Melbourne, Australia) and John Stanley (University of Sydney, Australia).

(C) 2017 by the author; licensee Cogitatio (Lisbon, Portugal). This article is licensed under a Creative Commons Attribution 4.0 International License (CC BY).

\section{Introduction}

The role of mobility in enabling access to life-enhancing opportunities has long been a focus of the research on social exclusion in cities (Cass, Shove, \& Urry, 2005; Lucas, 2012; Ricci, Parkhurst, \& Jain, 2016). One of the most insightful research strands on this topic is the work on gender based explanations of mobility-and accessibilityrelated social exclusion. This work has often drawn attention to shorter commutes and narrower spatial reach of women in searching for economic opportunities (e.g., Hanson \& Pratt, 1995). However, the depth of understanding of this phenomenon outside the North American and Western European contexts is limited (Kwan \& Schwanen, 2016; Uteng, 2011). Furthermore, the rising income and spatial inequalities, the changing na- ture of employment, work and household dynamics call for more recent analysis of the gendered differences in access and commuting patterns (Preston \& McLafferty, 2016).

The present article contributes to this debate by providing new evidence on gendered access and commuting patterns in two organised industrial zones (OIZs) in Turkey. The study specifically asks how gender plays a role in shaping access to the OIZs and commuting patterns of different social groups. Using a mixed method research design through the cases of Afyonkarahisar and Şanlıurfa, located in Central and Southeastern Anatolia respectively, the study pays particular attention to the interplay of local actors, household dynamics and workers' perceptions of accessibility to identify the employees' daily time and space constraints. It then goes on to 
discuss the implications of these constraints for access to economic opportunities.

Turkey has the lowest female labour participation rate $(32,5 \%$ as of 2016$)$ amongst OECD countries (OECD, 2017). Given that women's absence is even more prevalent in the production sector, the potential for women to benefit from the job opportunities in the OIZs has become important on the policy discourse (Kalkınma Bakanlığı, 2014). Turkey, therefore, provides us with a context, where it has been recognised that development planning should target increasing women's reach to industrial zones, hence an observation site to explore the complex dynamics of local institutions and daily space-time constraints in women's everyday life. OIZs are also usefulas they are historically seen as 'masculinised spaces' - in revealing the ways of how gender interplays with the dynamics within the workplaces (Wright, 2006). Afyonkarahisar and Şanlıurfa OIZs are of similar size and both include firms operating in female-dominated sectors. They are, however, subject to significantly different economic and social contexts at the provincial level, hence provide varied observations on access to work and commuting patterns that elucidate multifaceted aspects of the phenomenon.

\section{Literature Review}

There is significant academic interest on the interrelationships between mobility, gender and access to economic opportunities (Hanson, 2010). Many studies show that mobility could be an enabler for women to have better access to economic opportunities (e.g., Dobbs, 2005; Porter, 2008). There is also significant evidence on how constrained mobility and accessibility narrow down the opportunities for women's economic empowerment (Uteng, 2011). It is possible to classify this voluminous literature in terms of its relational focus. One group of studies focus on reporting the distinctive trends in the travel patterns of women and men (e.g., trip purpose and distance and transport mode) (e.g., Kwan \& Kotsev, 2015). This research strand has revealed important trends in unequal access of women to different modes of transport that have implications for their participation in society (Peters, 2013). These findings have been subject to a variety of interpretations, such as unequal household roles, emancipation, poverty, cultural contexts, which constitute the second group of studies (Hanson \& Hanson, 1981; Law, 1999; Porter, 2008). The third strand of this research has used the broader social, political and cultural implications of these trends to elucidate spatial inequalities in local labour markets (e.g., Hanson \& Pratt, 1995; Stuyck, Luyten, Kesteloot, Meert, \& Peleman, 2008).

The existing evidence relates mobility - and accessrelated economic exclusions of women to a variety of factors. Due to multiple tasks to be handled by women, most studies in this area have assumed time as a budget constraint, particularly in European contexts (Friberg, 1993). Some of the research on gendered mobilities also focuses on the features of how women travel to understand the implications of gendered mobilities for sustainability. The main motivation behind these studies has been the understanding of increasing diversity within cities and how to address a variety of social needs in the face of rapid urban development and environmental threats (Levy, 2013). Most of this research has been conducted from a transport studies perspective, in which mobility and accessibility are recognised to be the main factor in enabling access to citywide opportunities, such as access to jobs.

There is significant evidence that women seek to minimise time spent on the journey to work and that they tend to choose jobs that are closer to home (e.g., Anand \& Tiwari, 2006; Quiros, Mehndiratta, \& Ochoa, 2014). However, there are variations between different social groups. For instance, competing responsibilities for home and work alone do not explain the relatively longer commutes of higher educated women or distinctive characteristics of the commuting patterns of many minority women in New York (Preston \& McLafferty, 2016). Moreover, the studies that explain the complex interaction between economic, political and cultural contexts and the space-time constraints in everyday life of women are often limited to North American and Western European contexts. The gendered economic exclusions generated from space-time constraints in everyday life are gaining even more importance in rapidly urbanising regions. It is therefore imperative to understand the mobility-related economic exclusions of women across different social groups and contexts. The empirical focus of this article on the two Anatolian cities that are relatively underdeveloped compared to the rest of the country adds to the understanding of gendered access and commuting patterns.

\section{Research Design, Methods and Data}

While questionnaire based surveys provide a snapshot of travel trends within a group, they do not take into account the complex nature of everyday mobility and access affected by the local economic, cultural and political factors. A detailed look at the gendered mobilities is only possible through looking at multiple forms of data that can be obtained via a mixed method multiple case study design. The Afyonkarahisar and Şanlıurfa OIZs serve as two useful case study areas to explore, as they are of similar size in terms of both physical capacity and the number of firms, but are located in different economic (e.g., significant differences in employment and participation rates) and social contexts.

The study employed a triangulation of research methods including surveys; and semi-structured interviews with female employees, officers at the OIZ General Directorates, development experts, firm owners and firm managers (May-November 2014). A survey asking for specific residential and travel information together with other socioeconomic background and daily routine 
information was conducted in both OIZs. The questions included respondents' means of transport and length of commuting time, whether they changed residential locations to take up their jobs, and how much time they spend on household chores, as well as basic socioeconomic and household data (Carter \& Butler, 2008; Quiros, Mehndiratta, \& Ochoa, 2014; Schwanen, Kwan, \& Ren, 2014). The semi-structured interviews with the employees aimed at understanding the time-related difficulties that female employees face in their everyday life in terms of reaching their job locations. The interviews with the OIZ officers, development experts, firm owners and production managers helped gain a better understanding of the contexts and specify the sectoral focus of the research as well as bring in the employers' perception of women's time use.

Multi-level mixed method sampling was used to select the sectors, firms and employees for the survey. The sectors were identified on the basis of interviews with the OIZ officers and development planning experts at the Investment Offices who provided up-to-date information about the zones. Although the firms employing women were the main targets of sampling, the survey was also conducted with men in the same firms because the study considers 'gender' as a category rather than exclusively looking at women. Firms selected on the basis of purposive sampling were approached following the initial research that identified the firms that employ women. However, due to different company rules and regulations, not all firms took part in the survey. In Afyonkarahisar, 19 firms were approached; 15 of them agreed to conduct the survey with some of their employees. In Şanlıurfa, 22 firms were contacted and 14 of them ran the survey. The number of male and female respondents within the firms was intended to be proportional to the gender breakdown of the employees. However, although the response rate was 321 in Afyonkarahisar, and 221 in Şanlıurfa, some of the questionnaires were either incomplete or invalid. The limitations as such were considered in the data analysis.
The interviews with the employees were conducted in both zones (20 in Afyonkarahisar and 15 in Şanlıurfa). The sample included women with various socioeconomic backgrounds in the textiles, marble, construction, glass and food sectors. Five interviews with high level managers and firm owners in the textile, marble, service, glass and food sectors were held in Afyonkarahisar. In Şanlıurfa, firm owners and production managers of three companies in the textiles sector, and two managers in the metal and service sectors were interviewed. Finally, the two officers at the General Directorates of the OIZs and two experts at the Afyonkarahisar and Şanlıurfa Investment Offices were also interviewed.

The female-dominated sectors in Afyonkarahisar are textiles, communication, marble and food, while textiles and communications include the majority of the women in the workforce in Şanlıurfa. The female dominated sectors in the zones (i.e., services and textiles) are representative of the national population. In Afyonkarahisar, many women also work in the marble sector, particularly in its design part, which requires specific skills. The most relevant development at the time of the research was the upcoming opening of childcare facilities as part of the 'Mom's Work, My Future' project funded by a nationwide private company. The project aimed at increasing women's share of the employment in the OIZs by providing childcare facilities in the zones.

The description of the survey data is presented in Table 1. The sample of employees in Şanlıurfa OIZs is younger and less educated, earns slightly less and lives in larger households. While the gender ratios are comparable, the married proportion of the workforce sample in Afyonkarahisar is larger than that of the Şanlıurfa OIZ.

\section{Findings}

\subsection{Access to the OIZs}

The initial motivation behind establishing OIZs outside the centre of cities has been to move production out

Table 1. Description of the Afyonkarahisar and Şanlıurfa samples.

\begin{tabular}{lrrrr}
\hline & \multicolumn{2}{c}{ AFYONKARAHISAR } & \multicolumn{2}{c}{ ŞANLIURFA } \\
\cline { 2 - 5 } & $\mathbf{N}$ & Mean & N & Mean \\
\hline Age (years) & 309 & 30.97 & 186 & 25.77 \\
Education (years) & 317 & 11.24 & 192 & 9.39 \\
Salary (TL/month) & 321 & 1054.14 & 214 & 918.44 \\
Tenure (months) & 279 & 33.12 & 172 & 18.44 \\
Household size & 307 & 4.19 & 185 & 6.37 \\
Married (ratio) & 318 & 0.53 & 193 & 0.33 \\
Number of kids in the household & 246 & 1.47 & 121 & 2.45 \\
Number of people dependent on the respondent & 203 & 2.93 & 125 & 4.15 \\
Working hours & 321 & 8.72 & 214 & 9.05 \\
Household income (TL/month) & 213 & 1849.94 & 136 & 1526.62 \\
Gender (1 = Female) & 321 & 0.63 & 208 & 0.61 \\
\hline
\end{tabular}

Note: $\mathrm{N}=$ sample size. 
of cities. The OIZs were even described by one of the interviewees as a successful urban planning tool to reduce air pollution and other negative externalities that affect urban populations. The issues related to geographical accessibility of the OIZs are therefore not surprising. The provision of public transport services to the zones is, however, inadequate in both cities. There were almost no regular public transport services to the zones in the provinces at the time of the research, but the majority of the firms provided free company buses that ran at regular intervals depending on the working hours. There were also commercial minibuses that stopped outside the zones.

One of the key findings in terms of the gendered disparities in geographical accessibility of the OIZs concerns whether the employees changed their residential location as a result of taking up of their jobs at the OIZs. Only $10-15 \%$ of the respondents in each sample changed their residential location when they took up their jobs in the OIZs. The majority of those that moved because of the job opportunities were men. The fact that there are no women in either sample, who moved from another city to take up their jobs in the OIZs, is already indicative of the narrower spatial reach of female labour compared to male labour. The very few women who changed neighbourhoods moved for different reasons other than being physically closer to the OIZ.

For example, a 26-year old woman on a minimum wage moved to a neighbourhood that is further away from the OIZ, but is closer to her mother's home, where she drops her child off on the way to work so that her mother can look after her while she is at work. Childcare needs seem to play a role in the woman's choice of residential location as a result of taking up employ- ment at the OIZ. Another woman who also moved to a slightly remote neighbourhood when she was first employed at the OIZ is unmarried and lives with her relatives, whom she goes to work with. She mentions that going to work safely with her relatives is important to her family. These factors (i.e., being closer to childcare, going to work safely) in the choice of residential location due to employment reveal the multi-dimensional aspects of the spatial distribution of female labour.

The issues related to the geographical accessibility of the OIZs seem to affect the employees in different ways. As can be seen in the survey results, the dependence of the workforce on company buses is significant, which is expected given the lack of adequate public transport services (see Table 2). In both samples, the proportion of women who use company buses is higher by around $7-8 \%$ and the overall use of company buses ranges between $83 \%$ and $98 \%$ amongst male and female employees in both cities. A significant share of the women indicated that they would not work at the OIZ if company buses were not provided. Only $38 \%$ of the male respondents agreed with the statement in Afyonkarahisar, while this goes up to $78 \%$ in Şanlıurfa. The higher share of women who agreed with the statement may be due to their lack of willingness to take commercial minibuses that do not take them directly to the factories, but stop just outside the zones. Moreover, the share of the men who drive to work is slightly higher than that of women in Afyonkarahisar-something that may contribute to explaining why the male employees are relatively less dependent on company buses in the Afyonkarahisar OIZ. The gender differences in the dependence on company buses and the use of private cars almost disappear in Şanlıurfa, particularly amongst the manual unskilled labour-

Table 2. Description of the journey-to-work in the Afyonkarahisar and Şanlıurfa OIZs.

\begin{tabular}{|c|c|c|c|c|c|c|}
\hline & \multicolumn{2}{|c|}{ Female } & \multicolumn{2}{|c|}{ Male } & \multicolumn{2}{|c|}{ Total } \\
\hline & $\mathbf{N}$ & Mean & $\mathbf{N}$ & Mean & $\mathbf{N}$ & Mean \\
\hline \multicolumn{7}{|l|}{ AFYONKARAHISAR } \\
\hline Total travel time (minutes) & 201 & 69.68 & 120 & 63.16 & 321 & 67.24 \\
\hline If company bus wasn't available, I wouldn't go to work ( 1 = Agree) & 201 & 0.61 & 120 & 0.38 & 321 & 0.52 \\
\hline I wish I could just walk to work & 201 & 0.27 & 120 & 0.18 & 321 & 0.24 \\
\hline Use of private car (ratio) & 201 & 0.02 & 120 & 0.08 & 321 & 0.05 \\
\hline Use of company bus & 201 & 0.90 & 120 & 0.83 & 321 & 0.87 \\
\hline \multicolumn{7}{|l|}{ ŞANLIURFA } \\
\hline Total travel time & 127 & 68.43 & 81 & 56.90 & 208 & 63.67 \\
\hline If company bus wasn't available, I wouldn't go to work & 109 & 0.84 & 69 & 0.78 & 178 & 0.82 \\
\hline I wish I could just walk to work & 109 & 0.44 & 69 & 0.39 & 178 & 0.42 \\
\hline Use of private car & 127 & 0.02 & 81 & 0.02 & 222 & 0.02 \\
\hline Use of company bus & 127 & 0.98 & 81 & 0.90 & 222 & 0.92 \\
\hline
\end{tabular}

Notes: Transport mode was indicated in all of the questionnaires, but some of the questionnaires did not include the information on travel time. Travel time for these responses (20 questionnaires in Afyonkarahisar and 25 questionnaires in Şanlıurfa) was assumed to be the same with that of the respondents coming from the same neighbourhoods. The questionnaire also included minibuses, buses and walking in the list of transport modes with the aim of obtaining complete information on door-to-door travel to work, but very few respondents answered this question correctly (e.g., a 5 minute walk to the bus stop, where company buses leave, etc.). The analysis therefore included only the main transport modes used by the respondents. 
ers. This might yield insights into the importance of social group on dependence on the company buses.

We can also see clear trends in the overall perception of access to the OIZs. How the women see the ease of getting to the OIZ varies depending on their social groups (i.e., socioeconomic characteristics such as occupational status), particularly in Şanlıurfa. A middle-aged married woman holding a managerial position at a textile firm points out that the OIZ used to be far away from the centre of the city, but that it is no longer the case. A female accountant with relatively higher household income and no children, who gets a lift from her husband to get to work every day, shares this view by referring to company buses provided by the firms. A single female accountant working for a firm in Şanlıurfa that does not provide a company bus gets a lift from a close colleague (in place of a company car). When asked about the flexibility, she says, "When I am late, the company car waits for me." One of the older female managers said that the accessibility of the OIZ is even better compared to other workplaces in the city. The commonalities amongst all these positive attitudes are that these women come from relatively better socioeconomic backgrounds and have access to private transport. The situation differs for women who do not have access to alternative means of transport. All unskilled workers including cleaners and cooks interviewed in both cities list access to the OIZs as one of the main concerns, if not the biggest. Women working in firms that provide no company buses or company cars share this view on accessibility. In fact, in one of the smaller firms in the food sector, the female manager mentioned that although her employer gives her a lift if she wants it, she would prefer using a company bus as she thinks it gives her more independence.

Finally, it is worth noting the diversity of employers' thoughts on employing women in general, and their perceptions of women's access to OIZs more specifically for the significant consequences on women's working conditions. The owner of a large company, which employs only one woman as a cook, says that having female employees is a hassle for them by pointing out the immediate need for separate company buses for women and that they cannot take the responsibility for employing women. Not all firm owners agree, though. In fact, many of the owners, particularly in Şanlıurfa, emphasised that they wish they could employ more women, mainly because they are more obedient and disciplined. However, it was also mentioned that single women are more preferable because of the potential issues the employers see with married women with children, including taking time off work. This suggests strong assumptions over women's daily time use and priorities. All these observations regarding the image of female workers in the eyes of the employers in terms of work and mobility spaces have significant implications for female employees' working conditions.

\subsection{Commuting Times}

As seen in Table 3, the average commuting time is generally higher for women than men in both samples. This is not consistent with the general observation that women

Table 3. Commuting times.

\begin{tabular}{|c|c|c|c|c|c|}
\hline & & \multicolumn{4}{|c|}{ Average commuting time (minutes) } \\
\hline & & \multicolumn{2}{|c|}{ Afyonkarahisar } & \multicolumn{2}{|c|}{ Şanlıurfa } \\
\hline & & Male & Female & Male & Female \\
\hline \multirow[t]{2}{*}{ Marital status } & Single & 70 & 75 & 54 & 70 \\
\hline & Married & 59 & 64 & 58 & 56 \\
\hline \multirow[t]{3}{*}{ Education } & Primary & 55 & 55 & 57 & 65 \\
\hline & High School & 65 & 76 & 55 & 74 \\
\hline & University & 72 & 78 & 65 & 75 \\
\hline \multirow[t]{4}{*}{ Occupation } & NM unskilled & 80 & 89 & 69 & 96 \\
\hline & M unskilled & 57 & 54 & 57 & 68 \\
\hline & M skilled & 60 & 46 & n.a. & 50 \\
\hline & NM skilled & 59 & 55 & 43 & 40 \\
\hline \multirow[t]{5}{*}{ Age (yrs) } & $0-18$ & n.a. & 58 & 60 & 69 \\
\hline & $19-27$ & 71 & 74 & 56 & 69 \\
\hline & $28-34$ & 61 & 73 & 64 & 70 \\
\hline & $35-45$ & 56 & 61 & 51 & 55 \\
\hline & $46-55$ & 48 & 50 & 65 & 20 \\
\hline \multirow[t]{3}{*}{ Tenure category } & Less than a year & 58 & 75 & 57 & 67 \\
\hline & $1-2$ years & 68 & 68 & 45 & 89 \\
\hline & More than 2 years & 65 & 53 & 65 & 58 \\
\hline
\end{tabular}

Notes: NM: non-manual; M: manual. 
are likely to have shorter commutes. However, given that the location of jobs is the same for both genders in these samples and the alternatives to the jobs in OIZ are likely to be fewer in small cities like Afyonkarahisar and Şanlıurfa, shorter commuting times in general may not be meaningful to examine. However, the average commuting time for men and women broken down by other social categories yields interesting results.

Amongst the occupational groups, the largest difference in the Afyonkarahisar sample is between the female and male manual skilled workers (Table 3 ). The female employees in this group commute less than the men in the same occupational group. Women with high school education commute longer. These descriptive gender differences in commuting times accounting for occupational and educational levels already yield important results. The nonparametric statistical tests offer significant associations between commuting times and occupational groups and education levels. A Kruskal-Wallis test was conducted to determine whether the commuting times of women and men varied as a function of the socioeconomic categories. The results showed that in Afyonkarahisar, the occupational groups of the women relate to their commuting times $(\chi 2(3)=26.6, p<0.01)$, with unskilled female workers having higher mean ranks of commuting time (123.03 minutes for non-manual unskilled workers, 85.53 minutes for manual unskilled workers, 63.88 minutes for manual skilled workers and 82.45 minutes for non-manual skilled workers). There also exists a statistically significant positive correlation (Spearman's rho $=0.153, p<0.05$ ) between educational levels and commuting times amongst the female workforce of the Afyonkarahisar OIZ, while tests revealed insignificant results for men.

In the Şanlıurfa sample, there are significant gender differences in the average commuting times between men and women $(p<0.05)$. Accounting for the socioeconomic and household attributes, descriptive statistics yield further insights. Single women commute longer compared to single men, but commuting time is roughly the same for married men and women. The most important one is the significant difference in commuting times between unskilled female and male workers. While nonmanual unskilled women travel for around, on average, 96 minutes to get to work, this figure goes down to 69 minutes for non-manual unskilled men. Moreover, female workers with more education commute longer compared to men in the sample. In Şanlıurfa, the same statistical tests also confirm commuting times of the female employees varied as a function of their occupations $(\chi 2(3)=10.8, p<0.05)$ with a mean rank travel time of 62.28 minutes for non-manual unskilled workers, 67.19 minutes for manual unskilled workers, 39 minutes for manual skilled workers and 17.6 minutes for non-manual skilled workers. In contrast with Afyonkarahisar, no statistically significant correlation exists between education and commuting times for women in Şanlıurfa, and similar to Afyonkarahisar, there is also no statistically sig- nificant difference in commuting times amongst occupational groups within the male workforce.

The general perception of time use in everyday life reveals important differences amongst women from different educational and socioeconomic backgrounds. The women in higher social groups (i.e., educated, holding managerial positions with higher incomes) emphasise the time constraints they face in their everyday life, particularly in terms of balancing home and work responsibilities. Especially the young married women mention the extra burden they feel in terms of the household responsibilities. One of the newlywed women particularly points to the uneven distribution of household tasks between her and her husband and attributes this to society's expectations placed upon women. The situation changes for women in lower social groups (i.e., occupational groups): time becomes a constraint in reaching life-enhancing opportunities (e.g., vocational training and education) that would translate to more social mobility through getting better paid jobs that require specific skills. Many women holding low-paid, unskilled jobs stressed the need and desire for further training or continuing their education, but the lack of time emerged as an issue. When asked about the time-related constraints they face in their everyday life, young women working in low-paid jobs especially expressed a desire to attend training courses that would allow them to work independently.

Finally, time spent on commuting appears to be an important concern for firms, as they assume that it influences the productivity of workers. A senior level office manager in Şanlıurfa lists shorter commuting distance as one of the main benefits of moving operations from istanbul to Şanlıurfa: "at least 1-2 hours is spent on commuting in İstanbul, while in Şanlıurfa the longest distance would be 45 minutes without any delays. The employees perform better." Such a view echoes the previous evidence on how workers' (private) time is recognised as a direct input for the productivity of firms (Wright, 2006). However, the daily lives of different groups of women are more complex than this. Indeed, a 35-year old single woman with university education working in the Şanliurfa OIZ has two more jobs located far away from each other. She describes her day during term time:

I wake up, prepare breakfast, get ready for work, walk to the bus stop for 10 minutes, take the company bus...leave work to give some private tuition....Everyone in the household [she lives in a household of six] is financially dependent on me. I need other jobs.

Another female employee at a textile firm in Şanlıurfa with university education is doing her second (distance) degree. She spends most of her time on Sundays with her children, and then she does the housework until early in the morning. When considering such complex and intense daily routines of the women, the assump- 
tions made by employers with regards to women's time use have significant adverse implications for widening access to economic opportunities for women.

\section{Discussion}

Through the cases of Afyonkarahisar and Şanlıurfa, this article examined the commuting and accessibility patterns of women and men from different social backgrounds in the industrial zones in Turkey. The study particularly focused on whether and how gender plays a role in differences in access to the OIZs. The simultaneous analysis of qualitative and quantitative data revealed several key trends in terms of access to work, daily mobility patterns and wider reach to economic opportunities. Women do seem to make different choices about how to choose their place of residence for various reasons, such as being closer to childcare. This indicates the multidimensional nature of the spatial distribution of female labour. Moreover, women tend to have higher levels of dependence on free mobility services provided by their employers (i.e., company buses), especially in Afyonkarahisar. Despite the complex and unpredictable nature of everyday life of the female employees, the (male) employers' assumptions regarding women's time use as a result of life course changes also entail gender dimensions. It could, therefore, be argued that gender plays a role on the men and women's access to the zones in different ways.

However, women's socioeconomic and educational backgrounds seem to be more important predictors of commuting patterns than gender, while this is not the case for men. This difference tends to persist in the perceptions revealed by the study. How women see the accessibility of the OIZ varies depending on their social groups, particularly in Şanlıurfa. Women with higher social status and those with alternative (private) means of transport to get to work do not see any problems with accessing the OIZs. Women in this group perceive the daily time constraints arising from their household responsibilities as a pressing issue hence see the time spent on commuting as a more important constraint. Time becomes an issue for the women in lower social groups only when considering their desire to access to training and educational opportunities that would provide them with the means to higher social mobility (i.e., through getting better paid jobs). It is therefore possible to argue that time acts as a daily constraint for women in higher social groups, while its impacts upon the women in lower social groups in terms of reaching life-enhancing opportunities.

The results of the study seem to have two broader conceptual implications. First, while the gendered daily travel patterns provide a useful unit of analysis, they should be put in a wider context, whereby the economic, cultural and physical factors that affect work and mobility spaces of women can be identified. Most of the existing literature emphasise the implications of the negotiations that women have to make in private spheres for their participation in public life (e.g., Levy, 2013). The article demonstrates that a multi-scalar analysis of women's daily travel patterns reveals the significance of the socioeconomic dimension of women's access to work and wider opportunities. Second, the complex nature of everyday mobilities of women in lower social groups and their dependence on company buses should be interpreted in conjunction with the perceptions of employers. The employers' assumptions regarding the necessity of gendered mobility spaces and life course of women will prove problematic for these women's access to economy and eventually for social inclusion. Moreover, the perception of women's time use as a direct input for production presumes homogeneity amongst different social groups that may hinder varying vulnerabilities of female employees in the zones. It is, therefore, important to go beyond investigating the transport-specific characteristics of women's commutes (Peters, 2013; Uteng, 2011). Future research should evaluate the work-related mobilities of women in the wider governance and cultural contexts and bring in additional units of analysis, such as perceptions.

As can be seen from the combined explanatory power of the multiple forms of data, future research should use mixed methodologies to reveal the actual space-time constraints of women through daily mobility. Moreover, multi-level modelling of travel patterns should provide more detailed insights into different scales of spaces in which women work and live. As McDowell (2009) argues, even the study of small places like workplaces requires analysis of the contextual spatial processes. The study also reveals that the actual and perceived accessibility may change across different social groups; it should therefore be considered in future studies. From a policy perspective, top-down policies at the local level are likely to ignore the daily time-space constraints of women in different social groups. It is therefore imperative to identify the needs of the local women through participatory means, particularly of those needing to advance their skills for social mobility. Specifically, given the desire of the unskilled women holding low paid jobs to have access to training and educational opportunities, the provision of educational facilities in the zones has the potential to contribute to social mobility.

\section{Acknowledgements}

The author of this article acknowledges the support provided through the project "Increasing Women's Access to Economic Opportunities" organised by the World Bank Turkey (http://www.worldbank.org/en/country/turkey/ brief/explanation-on-call-for-research-papers-activity-of -increasing-womens-access-to-economic-opportunitiesproject). The contents of this document are the sole responsibility of the author. The complete findings of this project are documented in the main project report published in Turkish (http://documents.worldbank.org/ curated/en/docsearch/author/m1306633). The author 
would also like to thank the anonymous reviewers for their constructive feedback on the earlier version of this article.

\section{Conflict of Interests}

The authors declare no conflict of interests.

\section{References}

Anand, A., \& Tiwari, G. (2006). A gendered perspective of the shelter-transport-livelihood link: The case of poor women in Delhi. Transport Reviews, 26(1), 63-80.

Carter, P., \& Butler, D. (2008). Women's work: The home, the workplace, and the spaces between. The Industrial Geographer, 5(2), 3-18.

Cass, N., Shove, E., \& Urry, J. (2005). Social exclusion, mobility and access. Sociological Review, 53(3), 539-555.

Dobbs, L. (2005). Wedded to the car: Women, employment and the importance of private transport. Transport Policy, 12, 266-278.

Friberg, T. (1993). Everyday life: Women's adaptive strategies in time and space. Stockholm: Swedish Council for Building Research.

Hanson, S. (2010). Gender and mobility: New approaches for informing sustainability. Gender, Place \& Culture, 17(1), 5-23.

Hanson, S., \& Hanson, P. (1981). The impact of married women's employment on household travel patterns: A Swedish example. Transportation, 10(2), 165-183.

Hanson, S., \& Pratt, G. (1995). Gender, Work and Space. London: Routledge.

Kalkınma Bakanlığı. (2014). Imalat Sanayiinde Dönüşüm Özel Ihtisas Komisyonu Raporu, Onuncu Kalkınma Planı (2014-2018). Ankara: T. C. Kalkınma Bakanlığı.

Kwan, M. P., \& Kotsev, A. (2015). Gender differences in commute time and accessibility in Sofia, Bulgaria: A study using 3D geovisualisation. Geographical Journal, 181(1), 83-96.

Kwan, M. P., \& Schwanen, T. (2016). Geographies of mobility. Annals of the American Association of Geographers, 106(2), 243-256.

Law, R. (1999). Beyond 'women and transport': Towards new geographies of gender and daily mobility. Progress in Human Geography, 23(4), 567-588.

Levy, C. (2013). Travel choice reframed: 'Deep distribu- tion' and gender in urban transport. Environment and Urbanization, 25(1), 47-63.

Lucas, K. (2012). Transport and social exclusion: Where are we now? Transport Policy, 20, 105-113.

McDowell, L. (2009). Working bodies: Interactive service employment and workplace identities. London: Wiley-Blackwell.

OECD. (2017). Labour force participation rate by sex and age 2016. Retrieved from https://stats.oecd.org/ Index.aspx?DataSetCode=LFS_SEXAGE_I_R

Peters, D. (2013). Gender and sustainable urban mobility: Thematic study prepared for global report on human settlements 2013. Nairobi. Retrieved from https://unhabitat.org/wp-content/uploads/2013/06/ GRHS.2013.Thematic.Gender.pdf

Porter, G. (2008). Transport planning in sub-Saharan Africa II: Putting gender into mobility and transport planning in Africa. Progress in Development Studies, 8(3), 281-89.

Preston, V., \& McLafferty, S. (2016). Revisiting gender, race, and commuting in New York. Annals of the American Association of Geographers, 106(2), 300-310.

Quiros, T. P., Mehndiratta, S. R., \& Ochoa, M. C. (2014). Gender, travel and job access: Evidence from Buenos Aires gender and mobility. The difference is the speeds. Washington, DC: World Bank. Retrieved from http://siteresources.worldbank.org/INTURBANTRAN SPORT/Resources/2014-Feb-5-Gender-and-Mobility. pdf

Ricci, M., Parkhurst, G., \& Jain, J. (2016). Transport policy and social inclusion. Social Inclusion, 4(3), 1-6.

Schwanen, T., Kwan, M. P., \& Ren, F. (2014). The Internet and the gender division of household labour. Geographical Journal, 180(1), 52-64.

Stuyck, K., Luyten, S., Kesteloot, C., Meert, H., \& Peleman, K. (2008). A geography of gender relations: Role patterns in the context of different regional industrial development. Regional Studies, 42(1), 69-82.

Uteng, T. P. (2011). Gender and mobility in the developing world. World development report gender equality and development background paper. Washington, DC: World Bank. Retrieved from http://siteresources. worldbank.org/INTWDR2012/Resources/7778105-12 99699968583/7786210-1322671773271/uteng.pdf

Wright, M. W. (2006). Disposable women and other myths of capitalism. London: Taylor \& Francis.

\section{About the Author}

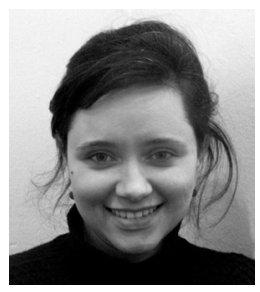

Nihan Akyelken (PhD) is an Associate Professor in Sustainable Urban Development in the Department for Continuing Education at the University of Oxford. She obtained her doctorate in Economic Geography from the University of Oxford, and her undergraduate and master degrees from the London School of Economics and Political Science in the areas of Economics and Philosophy and European Political Economy. Her research has largely been funded by the European Commission, the UK Research Councils, the British Council and the British Academy. 